\title{
Association Between Dementia and Common Geriatric Syndromes
}

\author{
(1) Duygu Erbas Sacar \\ Istanbul University Faculty of Medicine, Department of Internal Medicine, Division of Geriatrics, Istanbul, Turkey
}

\begin{abstract}
Objective: Dementia is a neurodegenerative disease characterized by a decline in cognition involving one or more cognitive domains (learning and memory, language, executive function, complex attention, perceptual-motor, social cognition). We aimed to assess the relationship of dementia with falls, urinary incontinence, polypharmacy, malnutrition, frailty and sleep disorders.
\end{abstract}

Materials and Methods: Two hundred and five individuals with the diagnosis of dementia and with no signs of dementia, who attended Istanbul University Faculty of Medicine geriatrics outpatient clinic, were retrospectively evaluated. Univariate and multivariate regression analyses were performed to investigate the association between dementia and other Geriatric syndromes.

Results: The mean age was $77.9 \pm 6.47$ years and $72.7 \%$ of the patients were female and $27.3 \%$ were male. The prevalence of dementia was $39.5 \%$ $(n=81)$. In univariate analysis, dementia was found to be associated with malnutrition ( $p=0.024)$, sleep disorders $(p=0.032)$, falls $(p=0.001)$, frailty $(p=0.037)$, male gender $(p=0.001)$ and polypharmacy $(p=0.001)$. In multivariate analysis, dementia was found to be independently associated with malnutrition ( $p=0.028$, odds ratio $=5.106,95 \%$ confidence interval $=1.189-21.932)$ and male gender $(p=0.001$, odds ratio $=3.407$, $95 \%$ confidence interval=1.786-6.500).

Conclusion: In our study, it was found that malnutrition and male gender were independently associated with dementia. Patients with neurodegenerative diseases are at risk of malnutrition, while reduced food intake is associated with disease symptoms. Geriatric syndromes increase mortality and morbidity in dementia patients. Therefore, clinicians should be aware of Geriatric syndromes in dementia patients.

Keywords: Dementia, malnutrition, urinary incontinence, falls, frailty

\section{Introduction}

Dementia is a neuropsychiatric syndrome characterized by cognitive decline and progressive deterioration of daily function, often associated with behavioral disturbances. Neurological disorders are now responsible for the largest number of disability-adjusted life years (a combined index of early mortality and years spent in disability). They now account for $10 \%$ of the global burden of disease. The prevalence of dementia in older participants is reported to be nearly $6 \%$ worldwide (1). It is probable that dementia is being underestimated, since in some parts of the world, patients with dementia never come to clinical attention. Dementia being considered as an inevitable consequence of aging (2) and, with global population ageing, it is expected to rise, although some recent studies have suggested declining trends in dementia frequency (3).

Dementia is any disorder where significant decline from one's previous level of cognition causes interference in occupational, domestic, or social functioning. Generally, dementia should be considered to be an acquired syndrome, with multiple possible causes, rather than a specific disease itself. For example, the dementia syndrome of progressive decline in language can be caused by various diseases, such as Alzheimer's disease (AD), a tumor in the language cortex, or frontotemporal lobar degeneration. Global estimates of dementia prevalence are up to $7 \%$ of individuals above the age of 65 , with a slightly higher prevalence (8-10\%) in developed countries due to longer life spans (1).

Address for Correspondence: Duygu Erbas Sacar, İstanbul University Faculty of Medicine, Department of Internal Medicine, Division of Geriatrics, İstanbul, Turkey

Phone: + 905556806431 E-mail: duyguerbassacar@gmail.com ORCID: orcid.org/0000-0002-3823-0878

Received: Jun 07, 2020 Accepted: Aug 03, 2020

Cite this article as: Erbas Sacar D. Association Between Dementia and Common Geriatric Syndromes. Eur J Geriatr Gerontol 2020;2(3):71-76

๑Copyright 2020 by the Academic Geriatrics Society / European Journal of Geriatrics and Gerontology published by Galenos Publishing House. 
$A D$ is the most common form of dementia in older people, accounting for $60 \%$ of cases. Numbers likely to increase given our ageing population. There are lots of concomitant problems progressing with dementia, like polypharmacy, malnutrition, sleep disorders, frailty, falls etc. Polypharmacy, the co-prescription of multiple drugs, is common and a particular concern amongst patients with dementia $(4,5)$.

According to the World Alzheimer Report 2018, about 50 million people worldwide lived with dementia in 2018, with the number projected to increase to 152 million by 2050 (6).

There are extensive range of risk factors associated with dementia such as smoking, alcohol abuse, and other noncommunicable diseases like diabetes mellitus, hypertension, hypercholesterolemia, metabolic syndrome, obesity which are listed as cardiometabolic risk factors and atrial fibrillation, chronic kidney disease etc. The risk of having dementia increased in older groups especially from the age of 65 or above (7).

Turkish Statistical Institute shows that life expectancy keeps growing in Turkey. So, we have to be prepared the problems of aging like dementia as well. This may lead to excessive health care cost in government budget. There is obvious relationship between dementia and other geriatric syndromes. If we know the association between them, we can avoid complications such as fall related fractures, malnutrition related prolonged hospitalization, incontinence related urinary infections etc. In that way increased living comfort level, reduced number of hospitalization, lowered number of medication usage for the patient to be sustained. The aim of the study to assess the relationship between dementia and falls, urinary incontinence (UI), polypharmacy, malnutrition, frailty and sleep disorders in our population.

\section{Materials and Methods}

Study participants were recruited among older adults $\geq 65$ years of age admitted to Istanbul University Faculty of Medicine, Department of Geriatrics outpatient clinic for the first time between a period of September 2015- August 2016 were evaluated retrospectively. Between study participants there were patients who have been medically diagnosed with dementia or showing signs and symptoms of dementia. Patients were evaluated retrospectively by a geriatrician using the patients' records on admission. Patients' data about number of chronic diseases and prescribed drugs; falls (in the preceding year); the presence of UI, frailty; nutritional status; sleep disorders; and dementia were noted. Dementia was diagnosed according to diagnostic and statistical manual of mental disorders, fifth edition criteria. UI was defined as "a complaint of any involuntary leakage of urine in the past 12 months" (8). Nutritional status was assessed by Mini Nutritional Assessment short form, which indicates the presence of malnutrition, malnutrition risk, and normal nutritional state when the score is 0-7 points, 8-11 points, and $>11$ points, respectively (9). Polypharmacy was defined as the daily use of five or more medications (10). Frailty was assessed by The International Association of Nutrition and Aging's FRAIL scale which includes five components; fatigue, resistance, ambulation, illness and loss of weight. FRAIL scale scores range $0-5 ; \geq 3$ represents frail, $1-2$ pre-frail and zero for robust health status (11). In our study FRAIL score $\geq 3$ was accepted frail and scores $<3$ non-frail. Sleep disorders components are insomnia and restless leg syndrome (RLS). Insomnia was assessed by asking the patients if they have experienced any difficulty in falling sleep and/or maintaining sleep (12). For evaluating RLS a single question was asked; do you experience unpleasant and restless feeling in your legs which is relieved by walking or movement (13). The study protocol has been evaluated and approved by Istanbul University Faculty of Medicine Ethics Committee (decision no: 90562, date: 05.06.2020). Informed consent was obtained from all the patients.

\section{Statistics}

The variables were assessed in terms of the normality of their distribution using the Kolmogorov-Smirnov test. Numerical variables with normal distribution were presented as mean \pm standard deviation and those with skewed distribution were presented as median (minimum-maximum). Categorical variables were shown as frequencies. For comparison of two groups, we used independent sample t-test or Mann-Whitney $\mathrm{U}$ test where appropriate. Chi-square test and Fisher's Exact test were used for comparison of non-numerical data. $P$ values less than 0.05 were accepted as statistically significant. Binary logistic regression models were used to investigate the association between variables. The factors found significantly associated with dementia in univariate analysis were further evaluated by logistic regression analysis. The IBM SPSS for Windows, version 22.0 (IBM Corp., Armonk, NY, USA) was used for statistical analysis.

\section{Results}

Among a total of 1.034 patients, 205 participants aged $\geq 65$ were included in this study. The sample was composed of women 149 $(72.7 \%)$ and men 56 (27.3\%). Mean age was $77.9 \pm 6.47$ years. Eighty-one patients (39.5\%) have a diagnosis of dementia. One hundred and eighty-eight (88.3\%) patients reported at least one fall in the previous year and 101 (48.8\%) patients have one of the sleep disorders. The frequency of UI is 58\%. $6.3 \%$ of the patients have malnutrition.

The characteristics of the study population including the age, number of drugs, dementia, nutritional status, UI, falls, and frailty are given in Table 1. 


\section{Univariate Analysis for the Association of Geriatric Syndromes and Dementia}

In univariate analysis dementia was not associated with UI $(p=0.149)$. In the other hand, dementia was found associated with malnutrition $(p=0.024)$, sleep disorders $(p=0.032)$, falls $(p=0.001)$, frailty $(p=0.037)$, male gender $(p=0.001)$ and polypharmacy $(p=0.001)$ (Table 2$)$.

\section{Multivariate Analysis for the Association of Geriatric Syndromes and Dementia}

Regression analysis was performed to find independent factors associated factors with dementia. Dementia was our dependent variable, and the independent variables were falls, sleep disorders, malnutrition, polypharmacy, frailty and male gender. A statistically significant relationship was found between malnutrition $[p=0.028$, odds ratio $(O R)=5.106,95 \%$ confidence interval $(\mathrm{Cl})=1.189-21.932]$ and male gender $(p=0.001$, $\mathrm{OR}=3.407,95 \% \mathrm{Cl}=1.786-6.500$ ) (Table 3 ) in regression analysis.

\section{Discussion}

As the population ages world wide, the overall burden of dementia is increasing simultaneously. Dementia may have more than one cause, particularly as the condition progresses and especially in older people. In addition, medical illnesses, comorbidities also some medications exacerbating poor cognition are common in

Table 1. General demographic data and geriatric syndrome data of the study population

\begin{tabular}{|l|l|}
\hline Male & $56(27.3 \%)$ \\
\hline Female & $149(72.7 \%)$ \\
\hline Age (years) & $77.9 \pm 6.47$ \\
\hline Dementia & $81(39.5 \%)$ \\
\hline Malnutrition & $13(6.3 \%)$ \\
\hline Frailty & $68(33.2 \%)$ \\
\hline Polypharmacy & $183(89.3 \%)$ \\
\hline Falls & $181(88.3 \%)$ \\
\hline Sleep disorders & $100(48.8 \%)$ \\
\hline Urinary incontinence & $119(58 \%)$ \\
\hline
\end{tabular}

older adult patients with dementia. Globally, an estimated 47 million people are affected by dementia (14).

$A D$ is the most common cause of dementia from middle age to the elderly and has a prevalence of 5-6\% of all individuals age 65 and above, and up to $30 \%$ in those over age 85 (15). In our study the frequency of dementia is $39.5 \%$. Our study population consist mainly from old subjects. Mean age was $77.9 \pm 6.47$ years. Therefore, our dementia prevalence is in accordance with the literature. In a Turkish study the prevalence of dementia was found $21.6 \%$ (16). This may be due to the presence of more advanced and older patients.

Advanced age and gender, two of the most prominent risk factors for dementia. Lifestyle factors such as smoking, excessive alcohol use and poor diet modulate sensitivity to dementia in both males and females. Depending on the subtype of dementia, the ratio of male to female prevalence differs. Females are at greater risk of developing $A D$ dementia, whereas males are at greater risk of developing vascular dementia or Parkinson disease dementia. Data from the Framingham study, which enrolled a total of 2.611 cognitively intact participants (1.550 women and 1.061 men) and followed-up on many for 20 years, indicated that for a 65-year-old man, remaining lifetime risk of $A D$ was $6.3 \%(95 \% \mathrm{Cl}, 3.9$ to 8.7$)$ and remaining lifetime risk of developing any dementing illness was $10.9 \%(95 \% \mathrm{Cl}, 8$ to 13.8$)$; corresponding risks for a 65-year-old woman were 12\% (95\% $\mathrm{Cl}, 9.2$ to 14.8$)$ and $19 \%(95 \% \mathrm{Cl}, 17.2$ to 22.5$)$, almost twice that of men (17). This can be particularly valid for subjects over the age of 85 years, due to differences in life expectancy.

Table 3. Logistic regression analysis for factors associated with dementia

\begin{tabular}{l|l|l|l|} 
Factor & \multicolumn{1}{c}{$\mathbf{p}$} & Odds ratio & $\begin{array}{l}\text { 95\% confidence } \\
\text { interval }\end{array}$ \\
\hline Malnutrition & 0.028 & 5.106 & $1.189-21.932$ \\
\hline Male gender & 0.001 & 3.407 & $1.786-6.500$ \\
\hline $\begin{array}{l}\text { Dependent variable was the presence of dementia; independent variables were female } \\
\text { gender and malnutrition (Factors included in the multivariate analysis are sleep } \\
\text { disorders, falls, frailty, polypharmacy, malnutrition and male gender) }\end{array}$ \\
\hline
\end{tabular}

Table 2. Univariate analysis for dementia and related factors

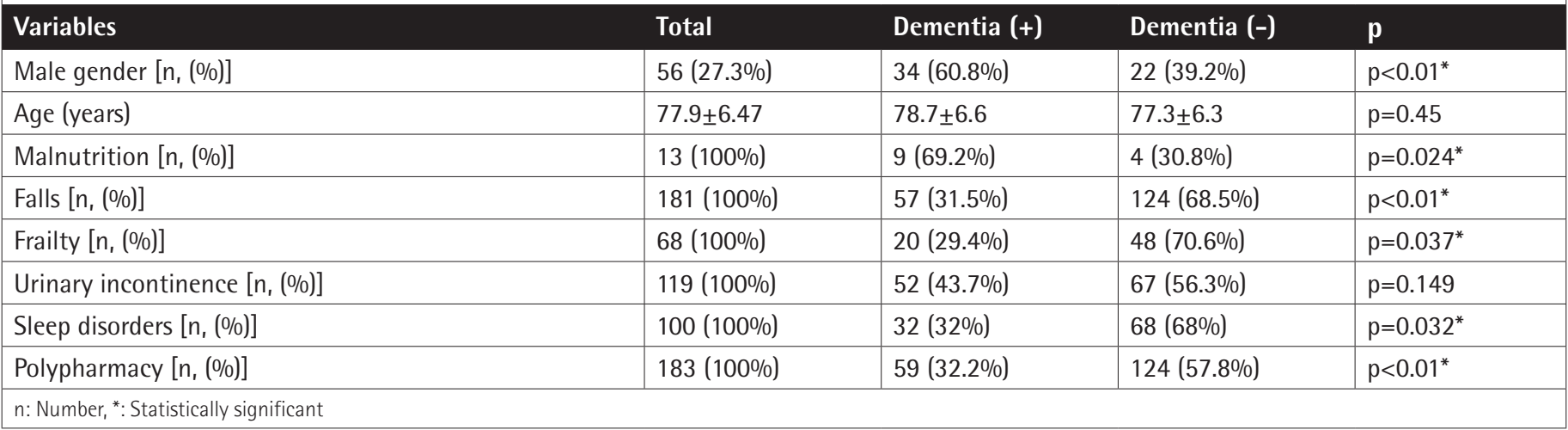


On the other hand, in our study male gender is highly associated with dementia $(p=0.001)$. We know that men with a Lewy body dementia and Parkinson disease dementia have a higher incidence of dementia than women across the age spectrum.

It is common for Alzheimer pathology to coexist with other processes, including vascular lesions, cortical Lewy bodies, argyrophilic grain disease, and Parkinson disease. The combination of two pathologies could influence the clinical presentation and course of the disease and present diagnostic challenges (18). The most common combination is that of $A D$ and vascular dementia. Mixed dementia is more common in males than females (19) and also in older age groups, such as those over 75 years. Although we do not know the dementia subtype of our patients, if we consider that the mean age of our patient population is high, we can interpret that the results are compatible.

We have found the malnutrition frequency is $6.3 \%$. In a study which was conducted in Japan, the prevalence of those with malnutrition in early-stage AD 8.2\% and were higher among those with early-stage $A D$ and the people who have normal cognition $(p<0.001)(20)$. In another Turkish prevalence study, the malnutrition prevalence is $9.6 \%$ (16). So, our results were also similar with the literature. In our study we found a significant relationship between malnutrition and dementia in both univariate analysis and bivariate analysis $(p=0.024$, $\mathrm{p}=0.028$ ). Inadequate nutrition is very common in patients with dementia and is associated with increased mortality (21). Decreased sense of smell is also common in dementia patients and can exhibit itself as weight loss and poor appetite. As a result, malnutrition develops in dementia patients. A few studies recently reported that nutritional problems, which are likely appetite changes, weight loss, and sarcopenia, start with mild cognitive impairment and early-stage $A D(22-25)$. There is no need for advanced dementia.

In our study the frequency of frailty was $33.2 \%$. Frailty is a common geriatric syndrome. Frailty is defined as a clinical state in which there is an increase in an individual's vulnerability to developing negative health-related events (including disability, hospitalizations, institutionalizations, and death) when exposed to endogenous or exogenous stressors (26). In most studies' frailty prevalence was 3.5\%-27.5\% (27). Frailty prevalence varies according to tool used. Also, we found a relationship between frailty and dementia in univariate analysis. Dementia is a progressive, debilitating disease which affects approximately half the residents in aged care impacting significantly on their care needs. Due to the inherent cognitive and physical decline over time, residents become increasingly dependent on care from others. Therefore, our frailty prevalence is close to upper limit. Also, we can explain the relationship between frailty and dementia by this.
Other important issue in the geriatric group is a number of a medication. Optimizing drug therapy is an important goal of caring for the older adult population. Polypharmacy is defined as the use of multiple medications and generally ranges from five to ten medications (10). Polypharmacy has been independently associated with an increased risk for an adverse drug event, and increased risk of hospital admission and length of stay (28). In our study the frequency of polypharmacy was $89.3 \%$. And we found a relationship between dementia and polypharmacy $(p<0.01)$. Also, we found a relationship between dementia and sleep disorders $(p=0.032)$. Vascular risk factors have been linked to increased risk of cognitive decline and dementia. These risk factors are diabetes mellitus, hypercholesterolemia, hypertension, metabolic syndrome and obesity. Therefore, the comorbidities of dementia patients are quite much and the number of drugs they use has increased. Our study population is older. The number of comorbidities of the patients with whose comorbidity data we had access to was high. On the other hand, sleep disorders and disturbances are common complaints among patients with dementia. Multiple factors contribute to sleep impairment in this population. Such as; age and dementia related changes in sleep and circadian rhythms, primary sleep disorders, comorbid illnesses and medications (29). Hypnotic use or sedating medication has also increased due to the frequent occurrence of sleep disorders in dementia patients, and this causes an increase in the number of drugs used by patients.

$\mathrm{UI}$ is more common in the elderly populations with dementia than without dementia. UI may complicate dementia morbidity and mortality. In our population $\mathrm{UI}$ frequency is $58 \%$. In most of the studies prevalence rates over 50 percent have been reported (30). In a Turkish study the prevalence of UI was found $47.6 \%$ (16). As a result, rates are at quite similar. We couldn't find a relationship between $\mathrm{UI}$ and dementia $(p=0.149)$. This is a surprising result. Although $\mathrm{UI}$ is a critical symptom and prevalent concomitant in patients with dementia, study about the association between $\mathrm{UI}$ and dementia is rare maybe because of the difficult assessment of $\mathrm{Ul}$ in patients with severe cognitive and physical deterioration. This result may be due to the low number of dementia patients.

\section{Study Limitations}

There are a number of limitations in this study. The sample size was not very large and especially we had few patients with dementia. This is a retrospective population-based study, so we did not have objective data including questionnaire, Dementia rating scale such as mini mental state examination. Therefore, the data did not provide information on stage and severity of dementia. Besides, we did not separate and analyze patients with dementia according to dementia subtype. This situation may affect the results. On the other hand, there are few studies 
evaluating the prevalence of dementia and possible related factors among community-dwelling older persons in Eastern Europe. Our study is one of the few studies in this area.

\section{Conclusion}

In our study we found high frequency of dementia among older adults in Turkey as much as 39.5\%. And dementia was highly associated with male gender and malnutrition. We have suggested the importance of screening other geriatric syndromes in dementia patients. It's known that, morbidity and mortality tend to increase due to these concomitant geriatric syndromes in dementia patients. If we screen specifically for these syndromes, we can prevent them faster. Therefore, more attention shall be paid to screening activities.

\section{Ethics}

Ethics Committee Approval: The study protocol has been evaluated and approved by Istanbul University Faculty of Medicine Ethics Committee (decision no: 90562, date: 05.06.2020).

Informed Consent: Informed consent was obtained from all the patients.

Peer-review: Internally peer-reviewed.

Financial Disclosure: The author declared that this study received no financial support.

\section{References}

1. Prince $M$, Bryce R, Albanese E, Wimo A, Ribeiro W, Ferri CP. The global prevalence of dementia: a systematic review and metaanalysis. Alzheimers Dement 2013;9:63-75.e2.

2. Alladi $S$, Hachinski V. World dementia: one approach does not fit all. Neurology 2018;91:264-270.

3. Grasset $L$, Brayne $C$, Joly $P$, Jacqmin-Gadda $H$, Peres $K$, Foubert-Samier A, Dartigues JF, Helmer C. Trends in dementia incidence: evolution over a 10year period in France. Alzheimers Dement 2016;12:272-280.

4. Lalic S, Sluggett JK, llomaki J, Wimmer BC, Tan EC, Robson L, Emery T, Bell JS. Polypharmacy and medication regimen complexity as risk factors for hospitalization among residents of long-term care facilities: a prospective cohort study. J Am Med Dir Assoc 2016;17:1067.e1-1067.e6.

5. Onder G, Lattanzio F, Battaglia M, Cerullo F, Sportiello R, Bernabei R, Landi $F$. The risk of adverse drug reactions in older patients: beyond drug metabolism. Curr Drug Metab 2011;12:647-651.

6. Alzheimer's Disease International. World Alzheimer Report 2018. London (GB): ADI; 2018: https://www.alz.co.uk/research/WorldAlzheimerReport2018.pdf. Accessed 2019 Jul 16.

7. Bich NN, Dung NTT, Vu T, Quy LT, Tuan NA, Binh NT, Hung NT, Anh LV. Dementia and associated factors among the elderly in Vietnam: a crosssectional study. Int J Ment Health Syst 2019;13:57.

8. Abrams $P$, Andersson KE, Birder L, Brubaker L, Cardozo L ,Chapple C, Cottenden A, Davila W, de Ridder D, Dmochowski R, Drake M, Dubeau C, Fry C, Hanno P, Smith JH, Herschorn S, Hosker G, Kelleher C, Koelbl H, Khoury S, Madoff R, Milsom I, Moore K, Newman D, Nitti V, Norton C, Nygaard I, Payne C, Smith A, Staskin D, Tekgul S, Thuroff J, Tubaro A, Vodusek D, Wein $A$, Wyndaele JJ, Members of Committees; Fourth International Consultation on Incontinence. Fourth international consultation on incontinence recommendations of the international scientific committee: evaluation and treatment of urinary incontinence, pelvic organ prolapse, and fecal incontinence. Neurourol Urodyn 2010;29:213-240.

9. Rubenstein LZ, Harker J0, Salvà A, Guigoz Y, Vellas B. Screening for undernutrition in geriatric practice: developing the short-form mininutritional assessment (MNA-SF). J Gerontol A Biol Sci Med Sci 2001;56:M366-372.

10. Ferner RE, Aronson JK. Communicating information about drug safety. BMJ 2006;333:143-145.

11. Morley JE, Malmstrom TK, Miller DK. A simple frailty questionnaire (FRAIL) predicts outcomes in middle aged African Ameris. J Nutr Health Aging 2012;16:601-608.

12. Roth T. Insomnia: definition, prevalence, etiology, and consequences. J Clin Sleep Med 2007;3(5 Suppl):S7-10.

13. Ohayon MM, O'Hara R, Vitiello MV. Epidemiology of restless legs syndrome: a synthesis of the literature. Sleep Med Rev 2012;16:283-295.

14. World Alzheimer Report 2015: The Global Impact of Dementia http://www. alz.co.uk/research/world-report-2015.

15. Hebert LE, Weuve J, Scherr PA, Evans DA. Alzheimer disease in the united states (2010-2050) estimated using the 2010 census. Neurology 2013;80:1778-1783.

16. Ates Bulut E, Soysal P, Isik AT. Frequency and coincidence of geriatric syndromes according to age groups: single-center experience in Turkey between 2013 and 2017. Clin Interv Aging 2018;13:1899-1905.

17. Seshadri S, Wolf PA, Beiser A, Au R, McNulty K, White R, D'Agostino RB. Lifetime risk of dementia and Alzheimer's disease. The impact of mortality on risk estimates in the Framingham Study. Neurology 1997; 49:1498-1504.

18. Galasko D, Hansen LA, Katzman R, Wiederholt W, Masliah E, Terry R, Hill $L R$, Lessin $P$, Thal $D$. Clinical-neuropathological correlations in Alzheimer's disease and related dementias. Arch Neurol 1994;51:888-895.

19. Knapp M, Prince M, Albanese E, Banerjee S, Dhanasiri S, Fernandez J. L, Stewart R. Dementia UK. London: Alzheimer's Society 2007.

20. Ai Kimura, Sugimoto T, Kitamori K, Saji N, Niida S, Toba K, Sakurai T. Malnutrition is Associated with Behavioral and Psychiatric Symptoms of Dementia in Older Women with Mild Cognitive Impairment and Early-Stage Alzheimer's Disease. Nutrients 2019;11:1951.

21. White H. Weight change in Alzheimer's disease. J Nutr Health Aging 1998;2:110-112.

22. Kai $K$, Hashimoto $M$, Amano $K$, Tanaka H, Fukuhara R, Ikeda M. Relationship between Eating Disturbance and Dementia Severity in Patients with Alzheimer's disease. PLoS ONE 2015;10:e0133666.

23. Suma S, Watanabe $Y$, Hirano $H$, Kimura A, Edahiro A, Awata $S$, Yamashita $Y$, Matsushita K, Arai H, Sakurai T. Factors affecting the appetites of persons with Alzheimer's disease and mild cognitive impairment. Geriatr Gerontol Int 2018;18:1236-1243.

24. Johnson DK, Wilkins CH, Morris JC. Accelerated Weight Loss May Precede Diagnosis in Alzheimer Disease. Arch Neurol 2006;63:1312-1317.

25. Sugimoto T, Ono R, Murata S, Saji N, Matsui Y, Niida S, Toba K, Sakurai T. Prevalence and associated factors of sarcopenia in elderly subjects with amnestic mild cognitive impairment or Alzheimer disease. Curr Alzheimer Res 2016;13:718-726.

26. Morley JE, Vellas B, Abellan van Kan G, Anker SD, Bauer JM, Bernabei R, Cesari M, Chumlea WC, Doehner W, Evans J, Fried LP, Guralnik JM, Katz PR, Mamstrom TK, McCarter RJ, Robledo LMG, Rockwood K, von Haehling S, Vandewoude MF, Walston J. Frailty consensus: a call to action. J Am Med Dir Assoc 2013;14:392-397.

27. Xue QL, Buta B, Varadhan R, Szanton SL, Chaves P, Waltson JD, Bandeen Rocke K. Frailty and geriatric syndromes. In: Satariano WA, Maus $M$, 
editors. Aging, place, and health: a global perspective. Burlington (MA): Jones \&t Bartlett Learning; 2017. p. 191-230.

28. Wimmer BC, Cross AJ, Jokanovic N, Wiese MD, George J, Johnell K, Diug B, Bell JS. Clinical Outcomes Associated with Medication Regimen Complexity in Older People: A Systematic Review. J Am Geriatr Soc 2017;65:747-753.
29. Pollak CP, Perlick D, Linsner JP, Wenston J, Hsieh F. Sleep problems in the community elderly as predictors of death and nursing home placement. J Community Health 1990;15:123-135.

30. Swenson, C, Solway, E, Singer, D, Kirch M, Kullgren J, Malani P. Urinary Incontinence: An Inevitable Part of Aging?. University of Michigan 2018. 